\title{
BENARKAH EQ LEBIH PENTING DARIPADA IQ?
}

\author{
Putri Lenggo Geni
}

Jurusan Psikologi, Fakultas Psikologi, Bina Nusantara University

Jl. Kemanggisan Ilir III No. 45, Kemanggisan, Palmerah, Jakarta Barat 11480

pl.geni@yahoo.com

\begin{abstract}
Emotional intelligence has gathered substantial attention from various communities and it is frequently considered as a miracle solution to remedy various psychological and social problems. In educational institutions and organization, general intelligence is still the main predictor in worker or student achievement objective indicators, such as productivity and GPA. These objective indicators is not the only source to measure workers or student or determining their achievements. Emotion is also greatly realted in the goal achievement of the related individual, therefore it is logic to assume that emotional intelligence is one of the factors determining success, performance and an individual's adaptive behavior
\end{abstract}

Keywords: emotional intelligence, general intelligence, objective indicators

\begin{abstract}
ABSTRAK
Kecerdasan emosional telah banyak mendapat perhatian luar biasa dari berbagai kalangan dan sering dianggap sebagai obat mujarab untuk mengatasi berbagai masalah psikologis dan sosial. Dalam institusi pendidikan maupun organisasi, kecerdasan umum masih merupakan prediktor utama dalam indikator objektif performa pekerja maupun siswa seperti produktivitas dan indeks prestasi kumulatif. Akan tetapi indikator objektif ini bukan sumber tunggal dalam menilai karyawan dan siswa ataupun menentukan keberhasilan mereka. Emosi juga erat kaitannya dengan pencapaian tujuan individu yang bersangkutan. Maka logis apabila kecerdasan emosional dianggap sebagai salah satu penentu dalam kesuksesan, kinerja, dan perilaku adaptif seseorang.
\end{abstract}

Kata kunci: kecerdasan emosional, inteligensi umum, indicator obyektif 


\section{PENDAHULUAN}

Dalam dua dekade terakhir, kecerdasan emosional atau emotional intelligence mendapat perhatian luar biasa, baik dari komunitas akademis maupun masyarakat awam. Istilah kecerdasan emosional yang pertama kali digunakan secara ektensif oleh Payne (1986) dalam disertasinya, baru menjadi populer sejak diterbitkannya buku Emotional Intelligence oleh Goleman (1995). Pesatnya penyebaran konsep kecerdasan emosional disebabkan oleh orientasi kebudayaan dan masyarakat saat itu, yang terlalu mementingkan kemampuan intelektual serta mengabaikan peran emosi (Matthew, Roberts, \& Zeidner, 2004).

Banyak klaim yang dikemukakan oleh pendukung pendekatan ini diantaranya kecerdasan emosional, yang seringkali diidentikkan dengan EQ atau emotional quotient, lebih penting daripada kemampuan intelektual atau IQ. Selain itu, EQ juga dianggap lebih dapat memprediksikan kinerja individu dalam pendidikan maupun pekerjaan dibandingkan kecerdasan umum. Kecerdasan emosional bahkan juga dinyatakan dapat memfasilitasi perkembangan serta meningkatkan proses kognitif seseorang (Gibbs, 1995; Goleman, 1995; Goleman, 1998).

Sejak beredar luasnya buku Goleman, berbagai intervensi dilakukan untuk meningkatkan kecerdasan emosional dilakukan dalam institusi pendidikan dan organisasi (Chernis, 2000). Intervensi untuk meningkatkan kecerdasan emosional dengan cepat dianggap sebagai obat mujarab untuk mengatasi berbagai masalah psikologis dan sosial (Matther, Roberts, \& Zeidner, 2004). Namun pihak yang skeptis berpendapat bahwa klaim-klaim ini lebih merupakan mitos dari pada ilmu pengetahuan dengan tidak adanya penelitian ilmiah yang terkontrol dan sistematis untuk membuktikannya (Mayer, Salovey, \& Caruso, 2004).

Berangkat dari kontroversi yang ada, artikel ini mencoba memaparkan isu-isu terkait dengan kecerdasan emosional, termasuk definisi konstruk, kesalahpahaman yang beredar luas di masyarakat, serta hasil-hasil penelitian khususnya mengenai implikasi kecerdasan emosional dalam perilaku, kinerja, maupun kehidupan sehari-hari.

\section{PEMBAHASAN}

Perbedaan pendapat di antara ilmuwan psikologi mengenai definisi dan cakupan kecerdasan emosional menambah kerumitan dalam upaya untuk mengukuhkan konsep ini dalam ranah ilmu pengetahuan dan tentunya juga menjadi tantangan dalam membuat alat ukur yang sahih. Menurut Goleman (1995), kecerdasan emosional merupakan semua kualitas positif di selain IQ yakni termasuk kemampuan untuk memotivasi diri dan bertahan dalam kondisi yang menimbulkan frustrasi, mengendalikan dorongan dan menunda keinginan, mengatur suasana hati dan menjaga stres agar tidak mempengaruhi proses berpikir, serta berempati.

Definisi dari Goleman seringkali dikritik karena cakupannya yang terlalu luas dan tumpang tindih dengan konstruk psikologis yang sudah ada seperti kepribadian (Bar-On, 2000). Walaupun demikian, Boyatzis, Goleman, dan Rhee (2000) mengembangkan Emotional Competence Inventory (ECI) untuk mengukur kompetensi emosional dan perilaku sosial yang positif yang dikelompokkan dalam empat ranah area yaitu kesadaran diri, kesadaran sosial, manajemen diri, dan keterampilan sosial. Kesahihan alat ukur ini masih dipertanyakan karena pengarang kurang terbuka terhadap upaya evaluasi oleh peneliti dalam bidang ini (Conte, 2005).

Dalam ulasannya yang cukup komprehensif, Mayer dan Salovey (1997) membagi kemampuan dan keterampilan dalam kecerdasan emosional menjadi empat area yaitu kemampuan untuk (a) mempersepsikan emosi orang lain yang ditunjukkan melalui ekspresi wajah, postur, dan bahasa tubuh, 
(b) menggunakan emosi untuk memfasilitasi proses berpikir baik dalam tahap perencanaan maupun pemecahan masalah, (c) memahami emosi, termasuk perubahan yang terjadi berikut konsekuensinya, dan (d) mengatur emosi dalam hubungannya dengan tujuan individu, kesadaran akan diri sendiri, serta lingkungan sosial.

Berdasarkan area-area tersebut, Mayer, Caruso, dan Salovey membuat alat ukur kecerdasan emosional yaitu Multifactor Emotional Intelligence Scale (Mayer, Caruso, \& Salovey, 2000) dan menyempurnakannya menjadi Mayer-Salovey-Caruso Emotional Intelligence Test (MSCEIT) (Mayer, Salovey, Caruso, \& Sitarenios, 2003). Selain ECI, MEIS, dan MSCEIT, alat ukur yang juga sering dipergunakan dalam konteks pendidikan dan organisasi adalah Bar-On Emotional Quotient Inventory (EQ-i) (Bar-On, 2000). Skala ini terdiri dari lima skala komposit yaitu intrapersonal, interpersonal, penyesuaian diri, mood, dan penglolaan stres. Dengan adanya alat-alat ukur tersebut, para ilmuwan psikologi kemudian dapat meneliti secara sistematis mengenai hubungan kecerdasan emosional dengan konsep lain, implikasinya dalam perilaku dan kinerja individu, serta efektivitas dari intervensi yang ditujukan untuk meningkatkan kecerdasan emosional.

Seperti telah disebutkan sebelumnya, para pengusung konsep kecerdasan emosional umumnya membuat klaim bahwa EQ dapat memprediksi kesuksesan individu, dalam pendidikan dan organisasi lebih baik daripada IQ (Goleman, 1998; Haygroup, 2000). Lebih spesifik, kompetensi emosional, yakni pengetahuan mengenai diri sendiri dan orang lain serta kemampuan untuk menggunakan pengetahuan ini untuk memecahkan masalah secara adaptif merupakan pondasi dalam proses belajar dan kesuksesan dalam bidang akademik (Cohen, 1999). Penelitian yang telah dilakukan untuk membuktikan hal ini memberikan hasil yang beragam. Parker, Summerfeldt, Hogan, dan Majeski (2004) menemukan bahwa skor EQ-i memprediksi 8 - $10 \%$ dari perbedaan dalam IPK mahasiswa semester satu (Parker, Summerfeldt, Hogan, Majeski (2004) dan bahkan prediksi yang lebih tinggi pada sampel siswa SMU (Parker, Creque, et al., 2004).

Hasil senada ditemukan dalam konteks organisasi, dimana skor EQ-i berkorelasi sedang $(\mathrm{r}=$ 0.22) dengan kinerja pada manajer pasar swalayan (Slaski \& Cartwright, 2002). Hasil yang lebih mengejutkan disimpulkan oleh Goleman (2001) berdasarkan analisa terhadap pemegang jabatan tinggi di 188 perusahaan besar (cth. British Airways, Credit Suisse). Ia membagi kemampuan personal menjadi tiga golongan yaitu keterampilan teknis seperti akuntansi dan perencanaan bisnis, kemampuan kognitif seperti daya analisa, dan kompetensi yang mencerminkan kecerdasan emosional seperti kemampuan untuk bekerja dengan orang lain dan efektivitas untuk memimpin perubahan, kemudian menentukan aspek yang paling berperan dalam kinerja mereka. Berdasarkan analisa tersebut, Goleman menemukan bahwa kecerdasan emosional dua kali lebih penting dibandingkan kualitas lainnya dalam memprediksi performa yang luar biasa, pada karyawan di semua tingkatan (Goleman, 2001).

Temuan dari penelitian-penelitian tersebut perlu dicermati secara hati-hati karena seringkali penelitian dalam bidang kecerdasan emosional merupakan penelitian internal yang tidak dipublikasikan atau diulas secara terbuka (peer reviewed). Dengan demikian, kontrol yang dilakukan boleh jadi sangat minim. Namun dengan interpretasi yang naif dan sorotan media, dampak temuan 'mentah' ini menjadi sangat meluas. Contohnya banyak penelitian yang tidak memisahkan aspek kepribadian yang dianggap tumpang tindih dengan konstruk kecerdasan emosional seperti faktor conscientiousness dalam five factor model yang hampir serupa dengan aspek pemecahan masalah dan tanggung jawab sosial dari EQ-i (McCrae, 2000).

Penelitian yang menyertakan dimensi kepribadian dalam analisanya justru menemukan korelasi yang sangat rendah antara skor EQ-i dengan indeks prestasi kumulatif (IPK) mahasiswa ( $\mathrm{r}=$ 0.01). Sebaliknya, kemampuan kognitif dan beberapa dimensi kepribadian (cth. kontrol diri) dapat memprediksi IPK secara seignifikan (Newsome, Day, \& Catano, 2000). Hasil yang serupa juga diperoleh dari lingkungan kerja dimana validitas alat ukur kecerdasan emosional sebagai prediktor performa dalam pekerjaan berada dalam rentang sedang, dan umumnya lebih kecil daripada IQ 
(Matthew, Roberts, \& Zeidner, 2004). Pengaruh kecerdasan emosional terhadap kesuksesan dan produktivitas tampaknya juga tidak langsung yaitu melalui kemampuan individu untuk mengatasi tuntutan lingkungan (Bar-On, 1997) dan penyampaian gagasan dengan cara yang menarik dan asertif sehingga menciptakan lingkungan kerja yang kondusif (Goleman, 1998).

\section{PENUTUP}

Berdasarkan tinjauan literatur di atas dapat disimpulkan bahwa dalam institusi pendidikan maupun organisasi, kecerdasan umum masih merupakan prediktor utama dalam indikator objektif performa pekerja maupun siswa seperti produktivitas dan indeks prestasi kumulatif. Akan tetapi indikator objektif ini bukan sumber tunggal dalam menilai karyawan dan siswa ataupun menentukan keberhasilan mereka. Faktor lain seperti integritas, kemampuan untuk bekerja dengan orang lain, sikap, dan pertahanan diri dari perilaku menyimpang (cth. membolos, penggunaan narkoba) yang dipengaruhi oleh berbagai faktor kognitif, emosional, maupun kepribadian memberikan kontribusi penting dalam kinerja individu dalam berbagai konteks.

Secara teoritis, emosi mengatur, memberikan tanda, dan memotivasi respon seseorang dalan situasi tertentu (Izard, 1993; Ekman, 2003). Emosi juga erat kaitannya dengan pencapaian tujuan individu yang bersangkutan. Maka logis apabila kecerdasan emosional dianggap sebagai salah satu penentu dalam kesuksesan, kinerja, dan perilaku adaptif seseorang sehingga ruang untuk penelitian masih sangat terbuka. Hanya saja sebarapa besar faktor ini berkontribusi dalam berbagai aspek dalam kehidupan manusia masih menjadi pertanyaan.

Sebagai konstruk yang relatif baru dibandingkan inteligensi, emosi, dan kepribadian, benyak penelitian dibutuhkan untuk menegakkan konseptualisasi kecerdasan emosional itu sendiri, terlepas dari kecerdasan umum, kepribadian, maupun kualitas lain yang semata-mata hanya menggambarkan preferensi atau perbedaan individual dalam berperilaku. Selain itu, diperlukan kontrol yang ketat dalam penelitian agar mendapatkan hasil yang valid, dapat digeneralisasikan, dan merumuskan hubungan sebab akibat. Dengan demikian, masyarakat dan media dapat memperoleh informasi yang akurat dan sesuai dengan proporsinya.

\section{DAFTAR PUSTAKA}

Bar-On, R. (2000). Emotional and social intelligence: Insights from the Emotional Quotient Inventory. In R. Bar-On \& J. D. A. Parker (Eds.), The handbook of emotional intelligence: Theory, development, assessment, and application at home, school, and in the workplace (pp. 363388). San Francisco: Jossey-Bass.Boyatzis, Goleman, dan Rhee (2000)

Cohen, J. (1999). Social and emotional learning: Past and present. In J. Cohen (ed.), Educating minds and hearts: Social emotional learning and the passage into adolescence (pp. 2-23). New York: Teachers College Press.

Conte, J. (2005). A review and critique of emotional intelligence measures. Journal of Organizational Behavior, 26, 433 - 440.

Ekman, P. (2003). Emotions revealed. New York: Times Books.

Goleman, D. (1995). Emotional intelligence. New York: Bantam. 
Goleman, D. (1998). Working with emotional intelligence. New York: Bantam.

Goleman, D. (2001). What makes a leader? In Harvard Business Review (pp. 1 - 25). MA: Harvard Business School Publishing.

Haygroup (2000). Emotional intelligence: A soft skill with a hard edge. Retrieved from http://ei.haygroup.com/about_ei/i.

Izard,C.E.(1993). Foursystemsforemotionactivation:Cognitiveand non-cognitive processes. Psychological Review, 100, 68-90.

Matthew, G., Roberts, R. D., \& Zeidner, M. (2004). Seven myths about Emotional Intelligence. Psychological Inquiry, 15, 179 - 196.

Matthew, G. Zeidner, M., \& Roberts, R. D. (2002). Emotional intelligence: Science \& Myth. MA: The MIT Press.

Mayer, J. D., \& Salovey, P. (1997). What is emotional intelligence? In P. Salovey \& D. Sluyter (Eds.), Emotional development and emotional intelligence: Educational implications (pp. 3-31). New York: Basic Books.

Mayer, J. D., Salovey, P., \& Caruso, D. R. (2004). Emotional intlligence: Theory, findings, and implications. Psychological Inquiry, 15, 197 - 215.

Mayer, J. D., Salovey, P., Caruso, D. R., \& Sitarenios, G. (2003). Measuring emotional intelligence with the MSCEIT V2.0. Emotion, 3, 97-105.

Newsome,S.,Day,A.L.,\& Catano,V.M.(2000). Assessingthepredictive validity of emotional intelligence. Personality and Individual Differences, 29, 1005-1016.

Parker, J. D. A., Creque, R. E., Barnhart, D. L., Harris, J. I., Majeski, S. A., Wood, L. M., Bond, B. J., \& Hogan, M. J. et al. (2004). Academic achievement in high school: Does emotional intelligence matter? Personality and Individual Differences, 37, 1321 - 1330.

Parker, J. D. A., Summerfeldt, L. J., Hogan, M. J., \& Majeski, S. (2004). Emotional intelligence and academic success: Examining the transition from high school to university. Personality and Individual Differences, 36, 163-172.

Payne, W. L. (1986). A study of emotion: Developing emotional in telligence: Self-integration; relating to fear, pain and desire. Dissertation Abstracts International, 47, 203A (UMI No. AAC 8605928).

Slaski, M., \& Cartwright, S. (2002). Health, performance and emotional intelligence: An exploratory study of retail managers. Stress \& Health, 18, 63 - 68. 